\title{
Differences of in children's motivation to brush their teeth using toothpaste and without toothpaste
}

\author{
Ade Sri Nengsih*, Eka Chemiawan*, Ratna Indriyanti* \\ *Departement of Pedodontics Faculty of Dentistry Universitas Padjadjaran
}

\begin{abstract}
Introduction: Motivation to brushing teeth consists of intrinsic and extrinsic factor. Extrinsic factor is the most influence to chlid's motivation. One of the extrinsic factor is toothpaste. The purpose of this study was to analyzed child's motivation differences between using toothpaste and without toothpaste. Method: This applied descriptive comparative research was using single blind method, with a sample size of 62 preschool children at Sekeloa, ranged from 4 to 6 years old. sampling technique using total sampling. The variables in this study were child's motivation and toothpaste. The tools and materials used in this study were motivation scale and tooth brushing activity sheets, informed consent, toothpaste, and toothbrushes. Result: The result shows that the highest motivational category on children who using toothpaste are 8 students $(25,81 \%)$, while on children without toothpaste are 3 students $(9,68 \%)$. Base on statistical analysis shows that a large motivational differences between children group using toothpaste and without toothpaste. Conclusion: There is a differences motivation between children that brush their teeth using toothpaste without toothpaste.
\end{abstract}

Keywords: Motivation, child, toothpaste, without toothpaste.

\section{INTRODUCTION}

The problem of cavities is experienced by many Indonesian people. Survey results proves that around 80 percent of Indonesians have cavities. ${ }^{1}$ Based on Health Research (Riskesdas), cavities are more common in children. Soendoro $T$ in his book explained that the population aged 12 and over and population below 12 years old have cavities approximately $43.4 \%$ and $89 \%$ in respectively. ${ }^{2}$

Cavities in children can be prevented by regular brushing. The results showed that brushing your teeth immediately after eating sweet foods can reduce the amount of tooth decay by $50 \%$. According to Axselsson and colleagues in the book Finn ${ }^{3}$, brushing your teeth twice a day with a minimum time of two minutes is effective for cleaning teeth from leftovers. Brushing teeth for two minutes is rarely done by children, especially in children under the age of five years. The results of the study mentioned that children aged less than five years, who brush their teeth without the accompaniment of a parent, brush their teeth for less than 20 seconds. $^{3}$

The habit of regular brushing is applied to children from an early age. Efforts to cause this habit have their own techniques. The most important way is to create an environment and activities that are fun for children. Motivation from parents and those around them really 
helps children to improve their behaviour so that children are easy to work with. Parents can attract children to brush their teeth, one of them by providing toothpaste and toothbrushes that are loved by children. ${ }^{4}$ Toothpaste produces foam or froth that attracts the child's attention when brushing their teeth so that brushing is fun for children. Toothpaste has a variety of flavour, ranging from the taste of fruit, mint, chocolate, or vanilla. The taste of pasta is generally liked by children. Children usually prefer non-spicy toothpaste. ${ }^{5}$ Information about differences on the effect of the use of toothpaste on children's motivation to brush their teeth is important for mother and children. The purpose of this study was to anlyzed differences of children's motivation to brush their teeth between using toothpaste and without toothpaste.

\section{METHODS}

This research is a comparative descriptive study. The population in this study were preschool children (4-6 years old) at Sekeloa Kindergarten in Bandung with 62 children who had characteristics of: students aged 4-6 years, boys and girls, and patient consent (Informed consent) that has been approved and signed by the student's parents. The study was conducted in April 2012 with a sampling technique using total sampling. The variables in this study were child's motivation and toothpaste. The tools and materials used in this study were motivation scale and tooth brushing activity sheets, informed consent, toothpaste, and toothbrushes.

Motivation in this study was measured using a questionnaire based on a motivational scale using a Likert scale with the criteria of questions consisting of the theory of needs satisfaction, process theory, and reinforcement theory. In this research questionnaire there are 4 choices of respondents' answers with different scores, namely: Strongly Agree $(\mathrm{SS})=4$, Agree $(\mathrm{S})=3$, Disagree $(T S)=2$, Strongly Disagree $(\mathrm{STS})=1$. Toothpaste used were toothpaste without flavour and white.

The step taken in this study is filling out informed consent sheets of research subjects that have been approved by parents. Then the researchers gave counselling to all study samples
(62 people) about the benefits of brushing teeth, how to brush teeth, brushing teeth done for two minutes, carried out twice a day morning after breakfast and at night before going to bed.

The study sample was divided into two randomly selected groups consisting of 31 people, namely the group using toothpaste (group A) and 31 groups not using toothpaste (group B). Researchers distributed toothbrushes with straight handles and yellowish clear color (same shape and color for all children) and toothpaste without taste to children in group $A$. Then the researchers distributed toothbrushes with the same shape and color to children in group B. Children were instructed to brush their teeth 2 times a day morning and night. Groups of children with toothpaste were instructed to brush their teeth using toothpaste that had been given. The group of children without toothpaste were instructed to brush without toothpaste. Both groups of children brush their teeth according to the instructions for one week by filling out the Tooth Brushing Activity Sheet (LKGM).

Researcher tried out the questionnaire piloted in kindergarten to test the validity of the questionnaire before conducting retrieval questionnaires on Sekeloa Kindergarten. The author did the same thing with 29 children by providing counselling and distributing toothbrushes and toothpaste. Then test the validity of the motivation scale with statistical calculations. One week later the researchers conducted interviews with children based on a questionnaire that had been prepared. Interviews were conducted by researchers with each child. The child alternately enters the room by bringing a Tooth Brushing Activity Sheet. Then the interview process is carried out based on the statements contained in the questionnaire. From the data that has been obtained, data is processed and analyzed using statistical analysis techniques using the $T$ test. Result obtained is presented in tabular form.

\section{RESULTS}

The results were obtained through an interview process based on a questionnaire on Bandung Kindergarten students with a range of age 4-6 years.

Table 1 shows that from a total of 31 
respondents, who were students of the Sekeloa Kindergarten, showing the frequency of students who brush their teeth using toothpaste in the moderate category were 14 students $(45.16 \%)$, in the low category were 9 students $(29.03 \%)$, while those in the high category are 8 students $(25.81 \%)$.

Table 2. shows that of the 31 respondents who were from Sekeloa Kindergarten students showed that the frequency of students who brush their teeth without using toothpaste in the medium category reached 16 students $(51.61 \%)$, in the low category were 12 students $(38.71 \%)$, while the smallest number is in the high category of 3 students $(9.68 \%)$. Child motivation to brush their teeth is divided based on the theory of needs satisfaction, process theory, and reinforcement theory. The following table illustrates the level of motivation of children from the three motivational theories.

Table 3. shows that from a total of 62 student respondents who were students of the Sekeloa Kindergarten, it turned out that in the group with toothpaste, the frequency of students

Table 1. Tabulation of frequency distribution of children for motivating brushing teeth with toothpaste

\begin{tabular}{ccc}
\hline Category & Frequency & Percentage \\
\hline High & 8 & $25.81 \%$ \\
Medium & 14 & $45.16 \%$ \\
Low & 9 & $29.03 \%$ \\
\hline Total & 31 & $100.00 \%$ \\
\hline
\end{tabular}

Table 2. Tabulation of children's frequency distribution for motivating tooth brushing without toothpaste

\begin{tabular}{ccc}
\hline Category & Frequency & Percentage \\
\hline High & 3 & $9,68 \%$ \\
Medium & 16 & $51.61 \%$ \\
Low & 12 & $38.71 \%$ \\
\hline Total & 31 & $100.00 \%$ \\
\hline
\end{tabular}

who had the motivation to brush their teeth on the theory of satisfying needs in the high and low categories had the same number of students as many as 11 people $(35.48 \%)$ and the moderate category has 9 people (29.03\%). Whereas in the group of students without toothpaste, the number of students in the low category was 17 students $(54.84 \%)$, in the medium category were 11 people $(35.48 \%)$, and in the high category were 3 people $(9,68 \%)$. Thus, it can be concluded that children's motivation to brush their teeth based on the theory of satisfying needs in both groups of students, is generally better in groups with toothpaste because the percentage of students who are in the high category is more than the group of students without toothpaste.

Table 4. showed that from a total of 62 student respondents who were students of the Sekeloa Kindergarten, it turned out that in the group with toothpaste, the frequency of students who had the motivation to brush their teeth on the theory of satisfying needs in the high category was as many as 20 people $(64.52 \%)$, in the medium category were 8 people $(25.81 \%)$, while in the low category there were 3 people $(9.68 \%)$. In the group without toothpaste, the number of students in the medium category was 17 people $(54.84 \%)$, in the low category were 10 people $(32.26 \%)$, while in the high category were 4 people $(12.90 \%)$.

Based on this description, it can be concluded that the motivation of children to brush their teeth on the theory of the process of two groups of students, is generally better in the group with toothpaste because the percentage of students who are in the high category is more than the group without toothpaste.

Table 5 showed that from a total of 62 student respondents who were from Sekeloa Kindergarten, it turned out that in the group with toothpaste, the frequency of students who had the motivation

Table 3. Tabulation of frequency distribution of respondent score categories for sub-table theory of need satisfaction theory

\begin{tabular}{cccccc}
\hline \multicolumn{5}{c}{ Satisfaction theory of needs } \\
\hline & Toothpaste & \multicolumn{4}{c}{ Without toothpaste } \\
\hline Category & Frequency & Percentage & Category & Frequency & Percentage \\
\hline High & 11 & $35.48 \%$ & High & 3 & $9.68 \%$ \\
Medium & 9 & $29.03 \%$ & Medium & 11 & $35.48 \%$ \\
Low & 11 & $35.48 \%$ & Low & 17 & $54.84 \%$ \\
\hline Total & 31 & $100.00 \%$ & Total & 31 & $100.00 \%$ \\
\hline
\end{tabular}


Table 4. The frequency of respondent responses related to questions about the habit of brushing teeth twice a day using toothpaste so that the teeth become healthy

\begin{tabular}{ccc}
\hline Respondents' responses & Frequency & Percentage \\
\hline Strongly agree & 15 & $48.39 \%$ \\
Agree & 16 & $51.61 \%$ \\
Disagree & 0 & $0.00 \%$ \\
Strongly Disagree & 0 & $0.00 \%$ \\
\hline Total & 31 & $100.00 \%$ \\
\hline
\end{tabular}

Table 5. Respondent frequency with questions regarding habit of brushing your teeth using toothpaste directly after meal

\begin{tabular}{ccc}
\hline Respondents' responses & Frequency & Percentage \\
\hline Strongly agree & 8 & $25.81 \%$ \\
Agree & 20 & $64.52 \%$ \\
Disagree & 3 & $9.68 \%$ \\
Strongly Disagree & 0 & $0.00 \%$ \\
\hline Total & 31 & $100.00 \%$ \\
\hline
\end{tabular}

to brush their teeth on the reinforcement theory which was in the low category was 12 students (38.71\%), at medium category is as many as 10 students $(32.26 \%)$, whereas in the high category is as much as 9 students (29.03\%). In the group without toothpaste the number of students in the high category was 16 students $(51.61 \%)$, in the medium category were 10 students (32.36\%), while in the low category there were 5 students $(16.13 \%)$.

Based on the description, it can be concluded that the motivation of children to brush their teeth on the theory of reinforcement from two groups of students, is generally better in the group without toothpaste because the percentage of students who are in the high category is more than the group with toothpaste.

\section{DISCUSSION}

The results showed that the group with toothpaste as a whole which occupies a high category in tooth brushing motivation were 8 students (25.81\%). In the group without toothpaste which occupy the high category were 3 students $(9.68 \%)$. The description shows that high motivation to brush teeth is more in the group of children who use toothpaste compared to the group of children without toothpaste. It can be concluded that high motivation in children to brush their teeth can occur due to the influence of the role of toothpaste that can motivate children to brush their teeth. This is consistent with the research conducted by Gill et al. ${ }^{6}$ which states that children are more eager to brush their teeth using toothpaste. Brushing teeth using toothpaste gives a fresh, clean and comfortable feel to the mouth so the child wants to brush teeth regularly. ${ }^{6}$ In accordance with the statement of Erlangga ${ }^{7}$ which states that regular use of pasta can refresh the mouth and can make teeth and gums healthy so that the use of toothpaste in the community has become a daily necessity. ${ }^{7}$

If seen based on the description of motivation theory in Ttable 4, the group with toothpaste occupies the highest category in the process theory $(64.52 \%)$. It can be concluded that the type of motivation that plays a major role in children's activities to brush their teeth using toothpaste is motivation that occurs because of the learning process of children to become better. This can happen because of parenting habits, parents instil good habits in brushing their teeth so that children know the importance of brushing their teeth for health. The description is in accordance with the statement of Gill et al. which states that the role of parents is very important in efforts to motivate children to brush their teeth. Research results show that children who brush your teeth every day accompanied by a parent complained less tooth decay than children brushing their teeth without in accompanied by a parent. The high motivation of children in the category of process theory can also be caused by an interesting learning process, namely counselling that has been conducted by researchers. ${ }^{6}$ In the group of children without toothpaste, the highest motivation is in the category of strengthening theory with a percentage of $51.61 \%$. This may occur because the awareness to brush teeth in the group without toothpaste is so low that it requires outside factors such as praise or punishment from parents to motivate children to brush their teeth.

Table 3 presents the frequency distribution of the score categories of children brushing their teeth based on the theory of satisfying needs. The total score of children in the low category of children without toothpaste is 17 children with a 
percentage of $54.84 \%$, which is the highest score on the theory of satisfying needs. The description states that children's motivation to brush their teeth based on the theory of satisfying needs which is an intrinsic factor is classified as low. This shows that the awareness of children to brush their teeth, which is an intrinsic factor, is very low. In accordance with the statement of Lepper, et al. ${ }^{8}$ which states that children's actions that occur due to intrinsic motivation are very low. Changes in behaviour that occur due to self-awareness are rarely found in children, especially children under the age of 6 years. Children are more motivated to take an action because of the influence of external factors, such as the encouragement of families, schools, and the environment. ${ }^{8}$

\section{CONCLUSION}

There is a differences motivation between children that brush their teeth using toothpaste without toothpaste.

\section{REFERENCES}

1. Mangoenprasodjo. Healthy teeth mouth awake. Yokyakarta: Thinkfresh. 2004. p. 24-
26.

2. Soendoro T. 2007 National Basic Health Research (RISKESDAS) Report. Jakarta: Health Research and Development Agency. 2008. p. 5.

3. Finn SB. Clinical pedodontic. Philadelphia: Saunders Company. 2003. p. 55-56.

4. Budiharto. Jurnal Kontribusi Perilaku Ibu dan Plak Gigi Anak terhadap Radang Gusi Anak. Jakarta: Fakultas Kedokteran Gigi Universitas Indonesia. 1997. p. 4-36.

5. Chang YC, Lo JL, Huang CJ, Hsu NY. Playful Toothbrush: Ubi Comp Technology for Teaching Tooth Brushing Kindergarten Children. Available from: http://www.citeseerx.ist. psu.edu.com [Cited 15 Jan 2012]. 2008.

6. Gill P, Stewart K, Chetcuti D, Chestnutt IG. Children's Understanding of and motivation for toothbrushing: a qualitiative study . Int $\mathrm{J}$ Dent Hyg. 2011 Feb;9(1):79-86.

7. Erlangga I. Application of SNI Toothpaste. Available from: http://www.BSN.co.id [Cited 6 May 2012]. 2003.

8. LepperMR, Sethi S, Dialdin D, Drake, M. Intrinsic and Extrinsic Motivation: A Developmental Perspective. New York: Cambridge University Press. 1997. p. 24-6. 